\title{
Research on the Construction of Practice Teaching System in Studio Teaching Mode
}

\author{
Chen Zhan, Zhifeng Jiang, Chenglong Dai \\ Wenzhou Vocational College of Science and Technology, Zhejiang, Wenzhou, 325000
}

Keywords: integration of training; research and entrepreneurship; studio teaching model; practical teaching; talent training

\begin{abstract}
Practical teaching is the vital component of higher vocational education. To carry out effective practical teaching is the key to improve the practical operational ability of students in higher vocational and technical colleges. This paper combines "the integration of training, research and entrepreneurship” with studio teaching model, as well as practical teaching. By taking students of digital media application technology major as targets, and the professional studio as reform platform, the curriculum teaching system has been reformed to form innovative teams of teachers and students to build the practical teaching platform of industry-university-research cooperation, so as to completely improve the practical operation ability of students majoring in digital media application technology.
\end{abstract}

\section{Introduction}

Higher vocational education takes the high-quality professional talents in production, construction, management and service as the basic tasks, and plays an irreplaceable role in building a great process of building a country with strong human resources and a strong country with higher education. In 2014, there were 1,066,000 students in vocational colleges across the country, the scale of which exceeded 10 million for the first time. Higher vocational education accounted for $40 \%$ of the total higher education. Higher vocational education has become the main basic force for training high-skilled personnel. The construction of a distinctive practical teaching system is the key to the success or failure of higher vocational education. The construction of practical teaching system can lay a solid foundation for the smooth development of all aspects of practical teaching in higher vocational education. The construction of digital media application technology professional practice teaching system is based on the professional talent training objective [1]. Through in-depth research and discussion with enterprises and employers, based on the industry characteristics, it understands the substantive needs of employers for professional personnel training. Exploratory construction of a practical teaching system based on the "training and research integration" studio teaching model.

\section{The Training Target for Digital Media Application Technology Professionals in Wenzhou Vocational College of Science and Technology}

The professional training of digital media application technology meets the needs of economic and social development and cultural inheritance and innovation, masters certain basic knowledge of digital technology and art design, and has the ability to track new trends, independently plan and produce project capabilities, and is responsible for the technical production, design, and planning of digital media posts. With the development of management, morality, physical beauty, and sustainable development, we are able to design and manage first-line high-end skilled talents. In order to realize the training objectives, the college implements the "dotted-line-body" curriculum system of the docking position, the docking profession, the docking industry, and the docking society to cultivate technical, innovative and entrepreneurial and compound digital media application talents [2]. 


\section{The Construction of Practical Teaching System Based on the "Integration of Training, Research and Innovation" Studio Teaching Model for Digital Media Application Technology Major}

According to the National Higher Vocational Education Development Plan (2011-2015) formulated by the Department of Higher Education of the Ministry of Education, the digital media application technology profession sets out from the characteristics of industry development and implements a talent cultivation model of work-study integration, school-enterprise cooperation, and post-internship training to comprehensively improve talents. Give full play to the functions of cultural education, integrate industries, enterprises, occupations, and other elements into campus culture, strengthen professional ethics and professionalism, and promote the coordinated development of students' knowledge, skills, and professional qualities. Based on social needs, it clarifies the goal of personnel training; consults professional post requirements, formulates professional talent training programs with industry companies; introduces industry enterprise technology standards, improves the dual certification system, and cooperates with schools and enterprises to jointly develop professional courses and teaching resources; Implement the teaching model reform of task-driven, project-oriented, order training, and engineering-replacement teaching as a whole; explore the establishment of a master studio, system design, implementation of productive training and internships, and close the school's teaching activities to the company's production process. In combination, schools and enterprises jointly complete teaching tasks and enhance the employment competitiveness of students [3].

Practical teaching refers to teaching activities that systematically organize students to grasp the theoretical knowledge and practical skills related to professional training goals through observation, experiment, and operation [4]. How to build a distinctive and effective practical teaching system has become the key to the success or failure of higher vocational education.

Training - training, training. With a professional studio as a platform, it fully integrates the real needs of society, integrates professional skills competitions, and builds a practical combat teaching system. The digital media application technology major is based on the visual communication design studio and the two professional studios of Yuema Creative Design Studio, and integrates professional close-cooperated external training bases (Bei Da Fang Printing Co., Ltd., Wenzhou Kingfisher Network Technology Co., Ltd., Wenzhou Yicun Culture Media Co., Ltd., Wenzhou Tiancai Technology Co., Ltd., and Shanghai Red Palm Visual Technology Co., Ltd.) jointly constructed this professional practice teaching system. Explore and improve the four levels of "cognitive practice level, basic ability training level, professional skills (technical) training level, and comprehensive practical level". "Four-level, five-module" integrated open-minded personnel training practical teaching the system shows. Constructing an integrated and open talent training practical teaching system such as experimental teaching modules, practical training modules, innovation and entrepreneurship modules, vocational qualification certificate modules, and graduation comprehensive practice modules. Through professional basic training based on professional basic skills, students are trained to master professional basic skills and professional basic practical skills; professional skills training based on studio-based professional practice and students' media production techniques and artistic thinking skills are preliminary. Through the company practice training in and outside the school practice base, improve the students' ability and quality of comprehensive application of professional knowledge and skills.

For students, the four levels of practice teaching are gradual and progressive, and are cultivated according to the integrated mode of production, study and research. Students are allowed to establish an open scientific and innovative thinking mode, combine theoretical knowledge with production practice, and integrate artistic innovation and technology. Combine practice and understand and sublimate theoretical knowledge in practice. Through practical project construction, some duplicate constructions and over-single practice projects have been removed or merged, and a number of comprehensive, design and innovative practical projects have been expanded, reconstructed, and newly built. Experimental teaching is closely integrated with innovative education to improve the sharing of resources. 
In the training process, the real projects of studios and training bases are closely integrated. The real projects of enterprises are introduced into the classroom through studios and other platforms to achieve real-life classroom teaching and improve the actual combat ability of elite students.

Give full play to the advantages of scientific research institutions in universities to form an expert group and jointly develop professional technologies with companies, share scientific research results, and provide services for the society. The strategy of "bringing in and going out" was introduced, and industry leaders and business experts were introduced into the college studio teacher team. The company's latest technology and ideas were introduced into the campus and students' initiative in participating in scientific research was activated. At the same time, let the studio professional teachers go out and combine the college's good policy on the training of full-time teachers in the company, let studio professional teachers deeply participate in the research and development of real projects, practically solve the practical difficulties of the company, and jointly promote the development of industrial research and development level. . To achieve a deep integration of professional and industry, to create a studio professional tutor team of "teachers coaching, special and combined, dual-complementary, and common development" to promote the full exploration and integration of professional, industry, and student tripartite wisdom resources and establish "three parties" The long-term mechanism for common growth creates a professional development community that effectively promotes the common development of "three parties" such as digital media professional tutors, students, and industry's excellent mentors, achieving a win-win situation for professional, industry, and students [5].

The digital media application technology program is based on the mentor studio and creates a student innovation and entrepreneurship studio. The Student Innovation and Entrepreneurship Studio utilizes a corporatized operating model to actively undertake design projects both inside and outside the college. The tutor conducts feasibility checks and quality control on each project, and introduces a representative entrepreneurial project into the classroom, using hierarchical teaching. In this way, the entrepreneurial project tasks with different degrees of difficulty are assigned to student teams with different levels of competence. The project design is completed by the student team in a competitive manner [6]. The tutor and the client together make public comments on the works of each team, and finally determine the successful bid. The student team will further follow up on the project's subsequent improvement and maintenance.

The operational flow of the "training and research integration" studio teaching mode is shown in Figure 2. The core idea should have the following characteristics:

(1) The establishment of a studio as a business, a student as an employee, is committed to fostering industry elites.

(2) Establish a real project production model based on actual projects and supplemented by competition projects.

(3) To establish the echelon training mode for juniors and seniors in senior year and second year.

(4) Taking the studio as a platform, the actual project will be introduced into the classroom, and the actual project will be implemented through the hierarchical teaching method combined with the curriculum training objectives.

(5) The introduction of competition mechanism, the use of bidding and bidding methods to operate the actual project, to further stimulate the subjective initiative of the student team, and effectively improve the project design quality.

(6) Reform of the curriculum evaluation mechanism. Through project defense, the operational effectiveness of the actual project will be displayed in all directions. The customer will review and give the major achievements of each team.

\section{Implementation and Reflection of the Practical Teaching System Based on the Integration of "Training, Research and Innovation" Studio Teaching Model}

The digital media application technology professional began researching and constructing the practical teaching system of the "Training Research and Integration” studio teaching mode in 2013. At present, the professional has 1 competition training team, 2 professional instructor workshops, 
and 5 student innovations. The Entrepreneurial Studio, five closely-typed off-campus practice teaching bases, and two professional student clubs, while effectively promoting professional development, have also greatly improved the practical ability of professional students.

In order to encourage professional students to actively participate in professional competitions at all levels, professional teams will regularly conduct competition training in the form of research projects of the "mentor + project + team" advocated by the college on the basis of the competition training team. Through the screening of actual combat items in the "Training, Research, Innovation and Integration" studio teaching model, it is determined that the participating projects will be promoted in the form of competitions and training teams, and the project design will be optimized. Since 2013, digital media application technology students have won a total of 1 national professional competition, 1 second prize, 15 second prizes, 8 third prizes, 2 second prizes in Zhejiang professional competitions, and 4 third prizes. .

The digital media application technology professional set up the first graphic design studio in the form of tutor-directed students in 2009. The visual communication studio, Yuema creative studio, and ingenious studio are now the main platforms, and the real project is Leading and improving the professional skills in the way of competition and training. Students participate in the teacher's project to cultivate the spirit of study, adhere to the original to strengthen the entrepreneurial, innovative spirit. Through the implementation in recent years, teachers and students have made great progress. The professional-related studio platform has undertaken more than 20 real projects of numerous organizations such as the Lucheng District CPPCC in Wenzhou City, Hunan Fenghuang Ancient City, Lai Renge Garments, and Wheat Impression Media. It integrates real projects with classroom teaching. Students lead through professional tutors. With guidance, multiple student innovation and entrepreneurship studios have begun to emerge, gaining widespread social attention and recognition. Many students started their business successfully. The "1933" photo studio startup studio run by Wei Xuming, a digital media 2012 graduate, focused on "the most beautiful passport photos". Due to its precise positioning and strong professional strength, it has opened three branches as a project start-up. The annual income of a person exceeds 300,000; annual income of the entrepreneurs of Hongfu, who is 13th in the digital media through a precision design project, exceeds 200,000; and that of Chen Xiang and Zhang Zhangchao, who are 13 in the digital media, follows the trend of the times. Development of virtual reality technology, introduction of venture capital technology to invest in the establishment of Wenzhou Kingfisher Network Technology Co., Ltd., specializing in the development and application of three-dimensional design, virtual reality technology, the first round of financing amounted to 5 million, has become the trend of the times.

The implementation of the practical teaching system based on the "Training and Research Integration" studio teaching model has achieved remarkable results. In 2013 and 2014, the average score of digital media technology students is lower than the college average score of 5 points; the average score of professional admission in 2015 is the same as the average score of college admission; in 2016, the average score of students in this major has been higher than the college average. With a score of 5 points, examinees' professional recognition increases year by year. According to the report on the quality evaluation of professional evaluation of Zhejiang Assessment Institute, the per capita starting salaries for digital media graduates increased by nearly 500 yuan compared with the 2013 graduates. The degree of graduates' satisfaction with their alma mater improved from the 8th to the full. In the fourth place, the professional employment rate has reached $100 \%$ for two consecutive years. From the above data, it can be seen that the practical teaching system of the "Training Research and Innovation Integration" studio teaching model has achieved remarkable results. The advantages of the digital media application technology profession are obvious, the professional characteristics are outstanding, and the social influence is increasing day by day.

The practical teaching system of the "training, research and creation integration" studio teaching mode has distinctive features and obvious advantages, but there are still certain problems in the course of operation. First of all, the studio actual combat project has a certain timeliness. How to 
combine the actual time-sensitive project and the regular classroom teaching plan organically becomes a major difficulty in the process of system construction. In order to take into account the regularity of the classroom, the tutor often gives up some of the very Excellent practical projects with high timeliness require a certain discount on the effectiveness of the practical teaching system of the "Training and Research Integration Studio" teaching mode. Secondly, the tutor plays a pivotal role in this practical teaching system. The amount of subsidies, but it is still difficult to fully reflect the value of the mentors in the entire practice teaching system during the operation of hard work. The era is advancing and the profession is developing. We believe that the future digital media application technology specialty can achieve more outstanding achievements in the implementation of the practical teaching system based on the "training and research integration" studio teaching model.

\section{Acknowledgements}

Fund Project: Research Achievements in Teaching Reform and Research Projects of Wenzhou Vocational College of Science and Technology, Project Title "Study on the Construction of Practice Teaching System for Digital Media Applied Technology Based on CDIO Concept"

\section{References}

[1] [5] Xia Lizhi. Construction and practice of "training, research and creation integration" practical teaching system in vocational gardening technology specialty: Taking Wenzhou Vocational College of Science and Technology as an example [J]. Modern agricultural science and technology, 2014(23), $341-343$.

[2] CHEN Xu. Research on the cooperation model of school-enterprise cooperation in digital media technology: A model of "Five-in-one" school-enterprise cooperation under the guidance of the team of supervisors [J]. New Campus (Theory), 2013(04), 53 -54

[3] Department of Higher Education, Ministry of Education. National Higher Vocational Education Development Plan (2011-2015). 2010.09.

[4] Meng Xinzheng. Vocational college employment-oriented practical teaching system research [D]. Lanzhou: Northwest Normal University, 2006:24.

[6] Xiao Hongyu. Vocational students' practical innovation ability training [J]. Education Review, 2014 (11), 66-68. 